\title{
Effect of Solute Stress and Temperature on Growth Rate and TRI5 Gene expression using real time RT-PCR in Fusarium graminearum from Spanish wheat
}

Patricia Marín ${ }^{1}$, Miguel Jurado ${ }^{1,4}$, Naresh Magan ${ }^{3}$, Covadonga Vázquez $^{2}$ and María Teresa González-Jaén ${ }^{1 *}$

${ }^{1}$ Department of Genetics and ${ }^{2}$ Department of Microbiology III, University Complutense of Madrid (UCM), Jose Antonio Novais 2, 28040 Madrid, Spain. ${ }^{3}$ Applied Mycology Group, Crandfield Health, Crandfield University, Crandfield, Bedford MK43 0AL, United Kingdom. ${ }^{4}$ Department of Molecular Microbiology, CIB, CSIC, Ramiro de Maeztu 9, 28040 Madrid,Spain

*Corresponding author: Prof. María Teresa González-Jaén, Department of Genetics, University Complutense Madrid, Jose Antonio Novais 2, 28040 Madrid, Spain. Tel.: +34 913944 830, Fax: +34 913944 844. E-mail: tegonja@bio.ucm.es 


\section{ABSTRACT}

The objective of this work was to study the effect of ecophysiological factors on trichothecene gene expression and growth in F. graminearum. The effect of non-ionic solute water potentials and temperature was examined on in vitro mycelial growth rates and on expression of the TRI5 gene, involved in trichothecene biosynthesis, quantified by real time RT-PCR. This study showed optimal values of $25^{\circ} \mathrm{C}$ and $-2.8 \mathrm{MPa}(0.982$ $\left.\mathrm{a}_{\mathrm{w}}\right)$ for growth. Marginal temperatures such as $15^{\circ} \mathrm{C}$ and $30-35^{\circ} \mathrm{C}$, particularly in combination with water potentials below $-2.8 \mathrm{MPa}$, drastically reduced growth. The induction of TRI5 was constant although some induction was observed between 20$30^{\circ} \mathrm{C}$, the most favourable temperatures for growth, depending on the water potential imposed, particularly at $-7.0 \mathrm{MPa}$. A temporal kinetic experiment at $25^{\circ} \mathrm{C}$ examined the effect of ionic solute stress on TRI5 gene expression and growth rate. The results indicated independence of growth rate and TRI5 expression, as the fungal biomass increased with time while the gene expression remained constant. This suggested that favourable conditions for growth will result in higher trichothecene production, and that toxin production would always accompany the colonization process at a steady rate while the conditions for growth are permissive. Quantification of key biosynthetic toxin genes by real time RT-PCR was shown to be a valuable tool to gain knowledge of the ecophysiological basis for trichothecene biosynthesis and enable better control strategies to be developed during the life cycle of this important mycotoxigenic pathogen of cereals. 
International Journal of Food Microbiology, Volume 140, Issue 2-3 (2010) 169-174.

Keywords: solute stress, temperature, TRI5 gene expression, ecology, growth, $F$. graminearum, trichothecenes

\section{INTRODUCTION}

F. graminearum Schwabe (teleomorph: Gibberella zeae (Schw.) Petch) is a widely distributed pathogen of cereal crops which causes important economic losses resulting in yield reduction, poor seedling germination and contamination of seed with toxins such as deoxinivalenol (DON), nivalenol (NIV) and zearalenone (ZEA) (Bai and Shaner, 1994; Snijders, 1990; Tuite et al., 1990). DON and NIV are trichothecene B mycotoxins. Consumption of food contaminated by these compounds by human and animals results in vomiting, alimentary hemorrhaging and dermatitis. These toxins are potent inhibitors of eukaryotic protein synthesis and induce apoptosis. ZEA has a high estrogenic activity. DON has also been associated with liver disease and esophageal cancer (Bennett and Klinch, 2003; Yazar and Omurtag, 2008). Because of the toxicity of these mycotoxins and their occurrence in cereals being close to the Tolerable Daily Intake values (TDI) they are is considered a health risk by Food Safety authorities (e.g. Science Committee on Food, 2000, 2002). Consequently, the European Union instituted legislation to protect the health of consumers and set limit values for DON, NIV and ZEA in unprocessed foods including cereals (EC 1881/2006; EC1126/2007).

The pathogen's life cycle is significantly influenced by environmental factors, especially water availability and temperature (Munkvold, 2003; Sanchís and Magan, 2004). Warm and rainy weather conditions at the flowering stage promotes infection of ripening ears by Fusarium spp., resulting in Fusarium Head Blight (FHB), predominantly caused by F. graminearum, one of the main Fusarium species of the 
complex causing this disease in many regions of Europe and world wide. Several studies have determined the optimum and marginal conditions for growth and for toxin production revealing differences in their boundaries (Hope and Magan, 2003; Hope et al., 2005; Jacobsen et al., 1993; Sanchís and Magan, 2004; Versonder et al., 1982). Although experimental conditions might have some influence on the results reported, intraspecific variability within $F$. graminearum might also have a strong impact since different species have been recently reported in the Fusarium graminearum species complex (Starkey et al., 2007). In other toxin-producing Fusarium species, such as $F$. verticillioides, the differences between permissive conditions for growth and toxin production are pronounced (Jurado et al., 2008).

Previous studies have identified that the effect of water availability $x$ temperature effects on germination, growth and DON production are all influenced by both ionic and non-ionic solutes (Hope et al., 2005; Magan and Lacey, 1984; Magan, 1988). However, very few studies have tried to link this data at a fundamental level to gene expression of key regulatory genes (e.g. TRI5 gene). TRI5 is the key gene of the trichothecene biosynthesis and encodes trichodiene synthase, which catalizes the first step in the trichothecene biosynthetic pathway, the isomerization and cyclation of farnesyl pyrophosphate to thrichodiene (Foroud and Eudes, 2009). Recent studies by Jurado et al. (2008) demonstrated the impact that changes in solute and matric water stress have on both growth and FUM1 gene expression, the key gene of fumonisin biosynthesis. This study showed for the first time that there was a significant stimulation of the FUM1 expression as ionic solute stress was imposed. This potential relationship of ecophysiological factors with the expression of key biosynthetic genes has not previously been explored for F. graminearum. 
A previous report has demonstrated a direct relationship between DON content and TRI5 expression $\left(r^{2}=0.95\right)$ measured by RT-PCR (Doohan et al., 1999). However, there are no studies which have examined the TRI5 gene expression in relation to ecophysiological factors. The quantification of TRI5 transcripts by real time RT-PCR permits a sensitive and specific approach to evaluate the effects of various abiotic and biotic treatments on trichothecene biosynthesis. This allows a much more sensitive method for examining the influence of ecophysiological conditions than conventional analyses of phenotypic mycotoxin production.

The objectives of this study were to use real time RT-PCR with the TRI5 as the target gene to (i) compare the effects of interacting conditions of temperature and water availability (non-ionic solute potential stress) on growth and TRI5 gene expression and (ii) evaluate the temporal kinetics of the effect of ionic solute potential on growth and TRI5 gene expression.

\section{MATERIALS AND METHODS}

\section{Fungal material}

A F. graminearum strain, FgB (L1-2/2D), was used. This strain was originally isolated from a wheat field in Lebrija, Sevilla, Andalucía, Spain, in April 2003. It belongs to lineage 7 (F. graminearum) (O'Donnell et al., 2000; O'Donnell et al., 2004). A previous analysis to characterize the chemotype of this strain indicated that it was a DON-producing chemotype having TRI13 and TRI7 disrupted or deleted (Jurado et al., 2006). The culture was maintained on potato dextrose agar medium (Scharlau Chemie, Barcelona, Spain) at $4^{\circ} \mathrm{C}$ and stored as spore suspensions in $15 \%$ glycerol at $-80^{\circ} \mathrm{C}$ in the Department of Genetics at UCM, Madrid, Spain. 


\section{Primer design and PCR amplification}

TRI5 sequences from the main trichothecene-producing species of Fusarium associated with cereals (F. graminearum: AY102605, AY102603 and AY102599; F. pseudograminearum: AY102585 and AY102583; F. culmorum: AY102602 and AY102571; F. poae: AY130294; and F. sporotrichioides: AF364179) were obtained from Genbank (National Center for Biotechnology Information database) and they were aligned by Clustal method using Dnastar (Lasergene, Madison, WI, USA). A primer pair was designed using the Primer Express ${ }^{\circledR}$ software (Applied Biosystems, Foster City, CA) for F. graminearum, F. culmorum and F. pseudograminearum on the basis of this DNA alignment. These primers were PQTRI5-MF (5' GATCTGATGACTACCCTCAATTCCTT $\left.\quad 3^{\prime}\right)$ and PQTRI5-MF (5' GCCATAGAGAAGCCCCAACAC 3'). The specificity of the PCR assay was assessed with genomic DNA from a number of $F$. graminearum species complex strains (Starkey et al., 2007) (NRRL 28585, F. austroamericanum; NRRL 28436, F. meridionale; NRRL 29020, F. boothii; NRRL 29148, F. mesoamericanum; NRRL 26755, F. acacia-mearsii; NRRL 13818, F. asiaticum; NRRL 29169, F. graminearum; NRRL 29306, $F$. cortaderiae) and either closely related or not closely related Fusarium species ( $F$. culmorum, Fcu2; F. sporotrichioides, ITEM 555; F.poae, MUCL 7555; F.equiseti, U6-11; F. proliferatum, FpMM12; F. verticillioides, FvMM12). All F. graminearum species complex strains amplified the expected 72 bp band, except F.cortaderiae. The closely related F. culmorum also showed an amplification band of the expected size. No amplification product was observed with DNA from the other Fusarium species tested. (data not shown). 
The pair of primers used to amplify TUB2 gene (the endogenous control gene used in the real time RT-PCR described below to normalize the results) was designed using the Primer Express ${ }^{\circledR}$ software (Applied Biosystems, Foster City, CA) with TUB2 sequences from the F. graminearum strains available in Genbank (AY781313, AY781312, AY781311, AY781310 and AY781309). As described above we performed the alignment of these sequences by the Clustal method using Dnastar (Lasergen, Madison, WI, USA). The primer pair designed for F. graminearum was TUB2PQ-PF (5' CCGAGGCCCAGTCCAACT 3') and TUB2PQ-PR (5' GGCGTCTTGGTATTGCTGGTA 3'). The specificity of the PCR assay was assessed with genomic DNA in a number of F. graminearum species complex strains (the same used above) and either closely related or not closely related Fusarium species (the same used above). An expected band of 59 bp was observed with all the Fusarium strains used (data not shown).

In all cases, the amplification reactions were performed in volumes of $25 \mu \mathrm{L}$ containing $100 \mathrm{ng}$ of template DNA in $3 \mu \mathrm{L}, 1.25 \mu \mathrm{L}$ of each primer $(20 \mu \mathrm{M}), 0.2 \mu \mathrm{L}$ of Taq DNA polymerase $(5 \mathrm{U} / \mu \mathrm{L}), 2.5 \mu \mathrm{L}$ of $10 X P C R$ buffer, $1 \mu \mathrm{L}$ of $\mathrm{MgCl}_{2}(50 \mathrm{mM})$, and $0.25 \mu \mathrm{L}$ of dNTPs (100 mM) (Ecogen, Barcelona, Spain). PCR was performed in a thermocycler (Eppendorf Mastercycler Gradient, Eppendorf, Hamburg, Germany). Amplification products were detected by electrophoresis on $2.5 \%$ agarose ethidium bromide gels in $40 \mathrm{mM}$ Tris-acetate and $1.0 \mathrm{mM}$ EDTA $1 \mathrm{X}$ buffer. The amplification protocol for both pairs of primers was: 1 cycle of $120 \mathrm{~s}$ at $94{ }^{\circ} \mathrm{C}, 35$ cycles of $35 \mathrm{~s}$ at 94 $\stackrel{\circ}{ } \mathrm{C}$ (denaturation), $30 \mathrm{~s}$ at $64{ }^{\circ} \mathrm{C}$ (annealing), $30 \mathrm{~s}$ at $72{ }^{\circ} \mathrm{C}$ (extension), and 1 cycle of $10 \min$ at $72^{\circ} \mathrm{C}$.

\section{Growth in relation to osmotic potential (ionic and non-ionic potential)}


International Journal of Food Microbiology, Volume 140, Issue 2-3 (2010) 169-174.

The medium used in this study was a trichothecene-inducing solid agar medium GYEP (glucose-yeast extract-peptone), which contained malt extract $(0.1 \%)$, peptone $(0.1 \%)$ and glucose $(0.5 \%)$.

The solute potential $\left(\Psi_{\mathrm{s}}\right)$ was modified either with the non-ionic solute glycerol to analyze the effect of the water stress and temperature on growth rate and TRI5 gene expression, or with the ionic solute sodium chloride $(\mathrm{NaCl})$ to perform the kinetics study. The solute potentials used were $-0.7,-2.8$ and -7.0 MegaPascals $(\mathrm{MPa}) \Psi_{\mathrm{s}}$, corresponding to water activities $\left(a_{w}\right)$ of $0.995,0.982$ and 0.955 , respectively. The solutes were not added to the control medium $\left(-0.7 \mathrm{MPa} \Psi_{\mathrm{s}}=0.995 \mathrm{a}_{\mathrm{w}}\right)$. All the treatments and replicate agar media were overlayed with sterile cellophane sheets (P400; Cannings, Ltd., Bristol, United Kingdom) before inoculation to facilitate removal of the fungal biomass for RNA extractions.

\section{Inoculation, incubation and growth assessment}

A 3-mm-diameter agar disk from the margin of a 7-day-old growing colony of FgB grown at $25^{\circ} \mathrm{C}$ was used to centrally inoculate each replicate and treatment. The plates were incubated at $15,20,25,30$ and $35^{\circ} \mathrm{C}$ for 10 days on the GYEP medium modified with glycerol. The experiment consisted of a fully replicated set of treatments with at least three replicates per treatment. Experiments were repeated once.

Assessment of growth was made daily during the 10-day incubation period. Two diameters of the growing colonies were measured at right angles to each other until the colony reached the edge of the plate. The radii of the colonies were plotted against time, and a linear regression was applied to obtain the growth rate as the slope of the line. 
An additional temporal experiment was carried out on the GEYP medium modified with $\mathrm{NaCl}$. This study was carried out at $25^{\circ} \mathrm{C}$ for $3,6,9$ and 12 days. Three independent replicates were destructively sampled at each time point and analyzed.

\section{RNA isolation and cDNA synthesis}

The biomass was removed from the cellophane at the end of the incubation period, and the total RNA extracted using the "Total Quick RNA cells and tissues" kit (Talent, Italy), according to the manufacturer's instructions, and stored at $-80^{\circ} \mathrm{C}$. DNase I treatment was used to remove genomic DNA contamination from the samples using "DNase I, amplification grade" (Invitrogen; United Kingdom), following the manufacturer's instructions. First-strand cDNA was synthesized using the "GeneAmp Gold RNA PCR reagent kit" (Applied Biosystems). Each $20 \mu \mathrm{L}$ reaction mixture contained $500 \mathrm{ng}$ of total RNA, $0.5 \mu \mathrm{L}$ of oligo(dT) ${ }_{16}(50 \mu \mathrm{M}), 10 \mu \mathrm{L}$ of $5 \mathrm{X}$ RT-PCR buffer, $2 \mu \mathrm{L}$ of $\mathrm{MgCl}_{2}(25 \mathrm{mM}), 2 \mu \mathrm{LI}$ of deoxynucleoside triphosphate (dNTP) (10 mM), $2 \mu \mathrm{L}$ of dithiothreitol (100 mM), $0.5 \mu \mathrm{L}(10 \mathrm{U})$ of RNase inhibitor $(20 \mathrm{U} / \mu \mathrm{L}), 0.3 \mu \mathrm{L}(15$ $\mathrm{U})$ of MultiScribe reverse transcriptase $(50 \mathrm{U} / \mu \mathrm{L})$, and sterile diethyl pyrocarbonatetreated water up to the final volume. Synthesis of cDNA was performed in a Mastercycler gradient thermal cycler (Eppendorf; Germany) according to the following procedure. After a hybridization step of $10 \mathrm{~min}$ at $25^{\circ} \mathrm{C}$, reverse transcription (RT) was carried out for $12 \mathrm{~min}$ at $42^{\circ} \mathrm{C}$. The cDNA samples were kept at $-20^{\circ} \mathrm{C}$. Samples incubated in the absence of reverse transcriptase were used as controls.

\section{Real time RT-PCR and quantitative analysis of the data}

Real time RT-PCR was used to amplify TRI5 and TUB2 cDNA from FgB using both pairs of primers described above. Real time RT-PCRs were performed using an 
ABI PRISM 7700 sequence detection system (Applied Biosystems). The PCR thermal cycling conditions for both genes were as follows: an initial step at $95^{\circ} \mathrm{C}$ for 10 min and 40 cycles at $95^{\circ} \mathrm{C}$ for $15 \mathrm{~s}$ and at $60^{\circ} \mathrm{C}$ for 1 min. SYBR green PCR master mix (Applied Biosystems) was used as the reaction mixture, with the addition of $2.6 \mu \mathrm{L}$ of sterile Milli-Q water, $1.2 \mu \mathrm{L}$ of each primer $(5 \mu \mathrm{M})$, and $5 \mu \mathrm{L}$ of template $\mathrm{cDNA}$, in a final volume of $20 \mu \mathrm{L}$. In all experiments, appropriate negative controls containing no template were subjected to the same procedure to exclude or detect any possible contamination or carryover. Each sample was amplified twice in every experiment. The results were normalized using the TUB2 cDNA amplifications run on the same plate. The TUB2 gene is an endogenous control that was used to normalize quantification of mRNA target for differences in the amount of total cDNA added to each reaction. In real time RT-PCR analysis, quantification is based on the threshold cycle $\left(C_{T}\right)$, which is defined as the first amplification cycle at which the fluorescence signal is greater than the minimal detection level, indicating that PCR products become detectable. Relative quantitation is the analytic method of choice for this study (Gizinger, 2002). The PCR efficiencies of both genes were measured by performing a 10 .fold serial dilution of positive control template to generate a standard curve, and by plotting the $\mathrm{C}_{\mathrm{T}}$ as a function of $\log _{10}$ of template. The slope in the standard curve for the amplification of the TUB2 gene was -3.22 while the slope in the standard curve for the amplification of TRI5 was -3.32. The efficiency of both pairs of primers was $104.26 \%$ and $99.71 \%$, respectively. Therefore, the PCR efficiencies to perform a real time RT-PCR experiment have to be between 90 and $105 \%$, and the slopes differences should be $\leq$ 0.1. In this method, a comparison within a sample is made with the gene of interest (TRI5) to that of the endogenous control gene (TUB2). Quantitation is relative to the control gene by subtracting the $C_{T}$ of the control gene from the $C_{T}$ of the gene of 
interest $\left(C_{T}\right)$. In graphic representations, we have used the average $C_{T}$ mean value of the three replicates performed in each experiment, and this was subtracted by the calibrator mean value of the three replicates to obtain the corresponding $C_{T}$ values. $C_{T}$ values were transformed to $\log _{2}$ (due to the doubling function of PCR) to generate the relative expression levels.

\section{Statistical analysis of results}

The linear regression of increase in radius against time (days) was used to obtain growth rates ( $\mathrm{mm} / \mathrm{day}$ ) as indicated above for each set of treatments. Analyses of variance were performed of the growth rates, TRI5 gene expression and temporal studies including the data of the three replicates from each experiment. All sets of results were evaluated by using StatGraphics Centurion XV.II (Statistical Graphics Corp., Herndon, VA). TRI5 gene expression data were transformed prior to analysis by $y=\log _{10}(T R I 5$ gene expression).

\section{RESULTS}

\section{Effects of temperature and non-ionic solute stress on growth rate}

Figure 1 shows the bi-dimensional map of relative growth rate of the FgB strain in response to non-ionic solute potentials (between -0.7 and $-9.8 \mathrm{MPa}$ ) and to temperatures $\left(15-35^{\circ} \mathrm{C}\right)$. The fastest growth was observed at $25^{\circ} \mathrm{C}$ and at $-2.8 \mathrm{MPa}$ $\Psi_{\mathrm{s}}\left(9-10 \mathrm{~mm} / \mathrm{day}^{1}\right)$, although growth rates were still high at $20^{\circ} \mathrm{C}$ and $30^{\circ} \mathrm{C}$ (7-8 and $6-7$ $\mathrm{mm} /$ day, respectively) at both -0.7 and $-2.8 \mathrm{MPa} \Psi_{\mathrm{s}}$. Solute water potential of $-7.0 \mathrm{MPa}$ or lower, severely reduced growth rate, particularly at marginal temperatures of $15^{\circ} \mathrm{C}$ or $30-35^{\circ} \mathrm{C}$. The ANOVA analyses of the effect of single factors considered in the study 
(temperature and solute potential) on growth rate, as well as the interaction of both factors indicated that single factors and their interactions were statistically significant (Table 1). At higher temperatures $\left(35^{\circ} \mathrm{C}\right)$ significant differences were not found between water stress levels of -0.7 and $-7.0 \mathrm{MPa} \Psi_{\mathrm{s}}$, while at higher water stress levels no significant differences were found between 15 and $35^{\circ} \mathrm{C}$ and 20 and $25^{\circ} \mathrm{C}$ (data not shown).

\section{Effects of temperature and non-ionic solute stress on TRI5 gene expression}

Figure 2 shows the relative $T R / 5$ gene expression pattern of FgB strain cultured for 10 days in response to both temperature and water potential. The ANOVA showed statistically significant effects for both single factors considered in the study (temperature, solute potential), whereas their interaction was not statistically significant (Table 2). TRI5 gene expression was significantly different among the three solute potentials, showing different gene expression profiles. At $35^{\circ} \mathrm{C}$ this was significantly different. The best conditions for TRI5 gene expression were at $-0.7 \mathrm{MPa} \Psi_{\mathrm{s}}$ between 20 and $30^{\circ} \mathrm{C}$ (Figure $2 \mathrm{a}$ ), and at $-7.0 \mathrm{MPa}$ between $20^{\circ} \mathrm{C}$ and $35^{\circ} \mathrm{C}$ (Figure $2 \mathrm{C}$ ). At -2.8 MPa $\Psi_{\mathrm{s}} T R I 5$ induction only occurred at 20 and $25^{\circ} \mathrm{C}$ (Figure $2 \mathrm{~b}$ ).

The standard error of the mean values of the two amplifications performed for each sample in the same plate, were generally very low (about $0.1 \%$ ) and never higher than $1 \%$, indicating a high reproducibility of the real time RT-PCR assay.

\section{Effect of ionic solute potential on temporal TRI5 gene expression}

Figure 3 shows the effect of ionic solute potential on relative growth rates, expressed as the area of colonization and induction of TR/5 gene expression of FgB at $25^{\circ} \mathrm{C}$ after $3,6,9$ and 12 days of cultivation. The results indicated that TRI5 mRNA 
synthesis remained very constant over the whole time course of the experiment, regardless of the ionic stress imposed.

\section{DISCUSSION}

This study produced a detailed two dimensional map showing the optimum, permissive and marginal rates of growth of the F. graminearum strain analyzed in relation to temperature and non-ionic solute stress. The permissive temperature conditions for growth were from $15-30^{\circ} \mathrm{C}$. However, growth was severely decreased at $35^{\circ} \mathrm{C}$, although optimal conditions were restricted to $25^{\circ} \mathrm{C}$. Water potential posed a severe restriction to growth at $-7.0 \mathrm{MPa} \Psi_{\mathrm{s}}$. This suggests that strains from various parts of Europe and those from South America behave in a largely similar way under these types of environmental stresses (Hope et al., 2005; Ramirez et al., 2006), and confirms the importance and prevalence of $F$. gramineraum in warmer regions. This growth pattern could also explain the lower incidence of this species in large areas of Spain, which are affected by frequent drought periods and high temperatures. The occurrence of this species has been lately reported also in cooler regions (Central Europe), and this has been explained by the increasing temperatures registered in the last few years (Waalwijk et al., 2003).

The clear influence of environmental conditions on growth, which produced clear profiles for optimal, permissive and marginal conditions for growth, contrasted with the profiles of TRI5 gene expression. In this case, TRI5 mRNA synthesis seemed to occur at a constant rate within a wider range of conditions, with slightly higher values at between $20-30^{\circ} \mathrm{C}$, particularly under higher water stress, and lower values at $35^{\circ} \mathrm{C}$. These results suggest that trichothecene biosynthesis might occur within a wider 
range of environmental conditions than those most favorable for successful colonization. However, the low induction of TRI5 gene detected under higher water stress (-7.0 Ma) supports the view that induction of mycotoxin genes might respond to stress (Schmidt-Heydt et al. 2008). This aspect might gain importance in regions where drought and mild temperatures are common, representing an additional risk for trichothecene contamination.

The information available from the literature on DON production also indicates a wide range of permissive conditions for DON production and some variation regarding the optimal conditions at between $25-30^{\circ} \mathrm{C}$ and water potentials between -0.7 and -2.8 MPa (Hope et al., 2005; Llorens et al, 2004; Ramírez et al., 2006; Versonder et al., 1982). On the other hand, in all these previous experiments, DON values were obtained after long incubation times (e.g. up to 40 days) and this might produce considerable variation among the studies. Over long incubation periods, physiological conditions might vary considerably among experiments affecting regulation of DON synthesis. Furthermore, DON might undergo degradation, and intermediate compounds might enter other related metabolic pathways resulting in variability in the amount of DON detected at the end of the experiments.

The study of the temporal kinetics of the effect of water stress on growth and $T R / 5$ expression, at the most permissive temperature for growth $\left(25^{\circ} \mathrm{C}\right)$, indicated a constant pattern of gene expression in all the ionic water stress conditions tested over the 12 day period. These results contrast significantly with those obtained for the fumonisin-producing F. verticillioides. Although in this case an uncoupling between growth and the key fumonisin biosynthetic gene (FUM1) expression was also observed, a marked induction of FUM1 expression was produced as water stress was imposed (Jurado et al., 2008). Overall, this suggests that favorable conditions for $F$. 
graminearum to grow will result in higher trichothecene production, and that toxin production would always accompany the colonization process within a wide range of conditions, although the contribution to the total toxin amount produced at optimal and permissive conditions for growth will be higher than the rest. This is supported by the high correlation reported previously between DON production and fungal mass (DNA amounts) in wheat samples (Fredlund et al., 2008; Schnerr et al., 2002; Waalwijk et al., 2004).

The different pattern observed for these two important Fusarium pathogens and toxin producers, F. graminearum and F. verticillioides, indicates the importance of regulation and suggests differences in the ecophysiological role that toxins might play in the lifecycle of these two species during host colonization. Furthermore, this type of information is essential in the development of climate based risk models for determining the potential for contamination of cereal grain with this trichothecene mycotoxin and to decide the most efficient strategies to control both growth and toxin production.

Acknowledments: This work was supported by the Spanish MCYT (AGL-2007-66416C05-02), and UCM-GR58/08-A (910672). P.M. was supported by FPI fellowship of the Spanish MCYT (BES-2005-8149).

\section{REFERENCES}

Bai, G.H., Shaner, G., 1994. Scab of wheat: prospects for control. Plant Diseases 48, 760-766. 
International Journal of Food Microbiology, Volume 140, Issue 2-3 (2010) 169-174.

Bennett, J.W., Klich, M., 2003. Mycotoxins. Clinical Microbiology Reviews 16, 497-516.

Commission Regulation (EC) No 1881/2006 of 19 December 2006 setting maximum levels for certain contaminants in foodstuffs. Official Journal of the European Union.

Commission Regulation (EC) No 1126/2007 of 28 September 2007 amending Regulation (EC) No 1881/2006 setting maximum levels for certain contaminants in foodstuffs as regards Fusarium toxins in maize and maize products. Official Journal of the European Union.

Doohan, F.M., Weston, G., Rezanoor, H.N., Parry, D.W., Nicholson, P., 1999. Development and use of a reverse transcription-PCR assay to study expression of tri5 by Fusarium species in vitro and in planta. Applied and Environmental Microbiology 65, 3850-3854.

Foroud, N.A., Eudes, F, 2009. Trichothecenes in Cereals Grains. International Journal of Molecular Sciences 10, 147-173.

Fredlund, E., Gidlund, A., Olse, M., Börjenson, T., Spliid, N.H.H., Simonsson, M., 2008. Method evaluation of Fusarium DNA extraction from mycelia and wheat for downstream real-time PCR quantification and correlation to mycotoxin levels. Journal of Microbiological Methods 73, 33-40.

Gizinger, D.G., 2002. Gene quantification using real-time quantitative PCR: an emerging technology hits the mainstream. Experimental Hematology 30, 503-512. 
Hope R., Magan, N., 2003. Two dimensional environmental profiles of growth, deoxynivalenol and nivalenol production by Fusarium culmorum on a wheat-based substrate. Letters in Applied Microbiology 37, 70-74.

Hope, R., Aldred, D., Magan, N., 2005. Comparison of the effect of environmental factors on deoxynivalenol production by $F$. culmorum and $F$. graminearum on wheat grain. Letters in Applied Microbiology 40, 295-300.

Jacobsen, B.J., Bowen, K.L., Shelby, R.A., Diener, U.L., Kemppainen, B.W., Floyd, J., 1993.Mycotoxins and mycotoxicoses.

http://www.aces.edu/Deparmentof/grain/ANR767.htm

Jurado, M., Vázquez, C., Callejas, C., González-Jaén, M.T., 2006. Occurrence and variability of mycotoxigenic Fusarium species associated to wheat and maize in South West of Spain. Mycotoxin Research 22, 87-91.

Jurado M., Marín, P., Magan N., González-Jaén, M.T., 2008. Relationship between solute and matric potential stress, temperature, growth and FUM1 gene expression in two Fusarium verticillioides strains from Spain. Applied and Environmental Microbiology 74, 2032-2036.

Llorens, A., Mateo, R., Hinojo, M.J., Valle-Algarra, F.M., Jiménez, M., 2004. Influence of environmental factor on the biosynthesis of type B trichothecenes by isolates of 
International Journal of Food Microbiology, Volume 140, Issue 2-3 (2010) 169-174.

Fusarium spp. from Spanish crops. International Journal of Food Microbiology 94, 4354.

Magan, N., Lacey, L., 1984. Water relations of some Fusarium species from infected wheat ears and grain. Transactions of the British Mycological Society 83, 281-285.

Magan, N., 1988. Effect of water potential and temperature on spore germination and germ tube growth in vitro and on straw leaf sheaths. Transactions of the British Mycological Society 90, 97-107.

Munkvold, G.P., 2003. Cultural and genetic approaches to managing mycotoxins in maize. Annual Review of Phytophatology 41, 99-116.

O’Donnell, K., Kistler, H.C., Tacke, B.K., Casper, H.H., 2000. Gene genealogies reveal global phylogeographic structure and reproductive isolation among lineages of Fusarium graminearum, the fungus causing wheat scab. Proceedings of the National Academy of Sciences USA 97, 7905-7910.

O’Donnell, K., Ward, T.K., Geiser, D.M., Kistler, H.C., Aoki, T., 2004. Genealogical concordance between the mating type locus and seven other nuclear genes supports formal recognision of nine phylogenetically distinct species within the Fusarium graminearum clade. Fungal Genetics and Biology 41, 600-623.

Ramirez, L., Chulze, S., Magan, N., 2006. Temperature and water activity effects on growth and temporal deoxynivalenol production by two Argentinean strains of Fusarium 
International Journal of Food Microbiology, Volume 140, Issue 2-3 (2010) 169-174.

graminearum on irradiated wheat grain. International Journal of Food Microbiology 106, 291-296.

Sanchis, V., Magan, N., 2004. Environmental profiles for growth and mycotoxin production. In Naresh, N. and Olsen, M. (Eds.), Mycotoxins in food: detection and control. Olsen. Woodhead Publishing Ltd. Cambridge, UK.

Schmidt-Heydt, M., Magan, N, Geisen, R. 2008. Stress induction of mycotoxin biosynthesis genes by abiotic factors. FEMS Microbiology Letters 284: 142-149.

Schnerr, H., Vogel, R., Niessen, L., 2002. Correlation between DNA trichotheceneproducing Fusarium species and deoxynivalenol concentrations in wheat-samples. Journal of Microbiological Methods 35, 121-125.

Scientific Committee on Food, 2000. Opinion of the Scientific Committee on Food on Fusarium toxins- Part 2 ${ }^{1}$ : Zearalenone (ZEA) (expressed on 22 June 2000).

Scientific Committee on Food, 2002. Opinion of the Scientific Committee on Fusarium toxins. Part 6: Group evaluation of T-2 toxin, HT-2 toxin, nivalenol and deoxynivalenol (adopted on 26 February 2002).

Snijders, C.H.A., 1990. Fusarium head blight and mycotoxin contamination of wheat, a review. Netherlands Journal of Plant Pathology 96, 187-198. 
Starkey, D. E., Ward, T. J., Aoki, T., Gale, L. R., Kistler, H. C., Geiser, D. M., Suga, H., Tóth, B., Varga, J., O’Donnell, K. 2007. Global molecular surveillance reveals novel Fusarium head blight species and trichothecene toxin diversity. Fungal Genetics and Biology 44: 1191-1204.

Tuite, J., Shaner, G., Everson, R.J., 1990. Wheat scab in soft red winter wheat in Indiana in 1986 and its relation to some quality measurements. Plant Diseases 74, 959-962.

Versonder, R.F., Ellis, J.J., Kwolek, W.F., DeMarini, D.J., 1982. Production of vomitoxin on corn by Fusarium graminearum NRRL 5883 and Fusarium roseum NRRL 6101. Applied and Environmental Microbiology 43, 967-970.

Waalwijk, C., Kastelein, P., de Vries, I., Kerényi, Z., van der Lee, T., Hesselink, T. Köhl, J., Kema, G. 2003. Major changes in Fusarium spp. In wheat in the Netherlands.

European Journal of Plant Pathology 109 (7): 743-754

Waalwijk, C., van der Heide, R., de vries, I., van der Lee, T., Schoen, C., Costrelde Corainville G., Häuser-Hahn, I., Kastelein, P., Köhl, J., Lonnet, P., Demarquet, T., Kema, G., 2004. Quantitative detection of Fusarium species in wheat using TaqMan. European Journal of Plant Pathology 110, 481-494.

Yazar, S., Omurtag, G.Z., 2008. Fumonisins, Trichothecenes and Zearalenone in Cereals. International Journal of Molecular Sciences 9, 2062-2090. 
International Journal of Food Microbiology, Volume 140, Issue 2-3 (2010) 169-174. 
International Journal of Food Microbiology, Volume 140, Issue 2-3 (2010) 169-174.

Table 1: ANOVA of the effects of temperature $\left(15,20,25,30\right.$ and $\left.35^{\circ} \mathrm{C}\right)$ and non-ionic (glycerol) solute potential $(-1.4,-2.8$ and $-7.0 \mathrm{MPa})$ and their interaction on growth rate.

\begin{tabular}{cccc}
\hline Source of variation & Df $^{\mathbf{a}}$ & Mean square & $\mathbf{F}^{\mathbf{b}}$ \\
\hline Temperature & 4 & 264.691 & $2769.47^{*}$ \\
\hline$\Psi_{\mathrm{s}}$ & 2 & 211.733 & $2215.37^{*}$ \\
\hline Temperature vs $\Psi_{\mathrm{s}}$ & 8 & 17.851 & $186.78^{*}$ \\
\hline
\end{tabular}

${ }^{a}$ Df: Degrees of Freedom, ${ }^{b}$ Snedecor's F Test. *, significant at $\mathrm{P}<0.05$ 
International Journal of Food Microbiology, Volume 140, Issue 2-3 (2010) 169-174.

Table 2: ANOVA of the effects of temperature $\left(15,20,25,30\right.$ and $\left.35^{\circ} \mathrm{C}\right)$ and non-ionic (glycerol) solute potential (-0.7, -2.8 and $-7.0 \mathrm{MPa})$ and their interaction on TRI5 gene expression.

\begin{tabular}{cccc}
\hline Source of variation & Df $^{\mathbf{a}}$ & Mean square & $\mathbf{F}^{\mathbf{b}}$ \\
\hline Temperature & 4 & 0,552501 & $5,56^{\boldsymbol{*}}$ \\
\hline$\Psi_{\mathrm{s}}$ & 2 & 2,9115 & $29,29^{*}$ \\
\hline Temperature vs $\Psi_{\mathrm{s}}$ & 8 & 0,131654 & 1,32 \\
\hline
\end{tabular}

${ }^{a}$ Df: Degrees of Freedom, ${ }^{b}$ Snedecor's F Test. *, significant at $\mathrm{P}<0.05$ 


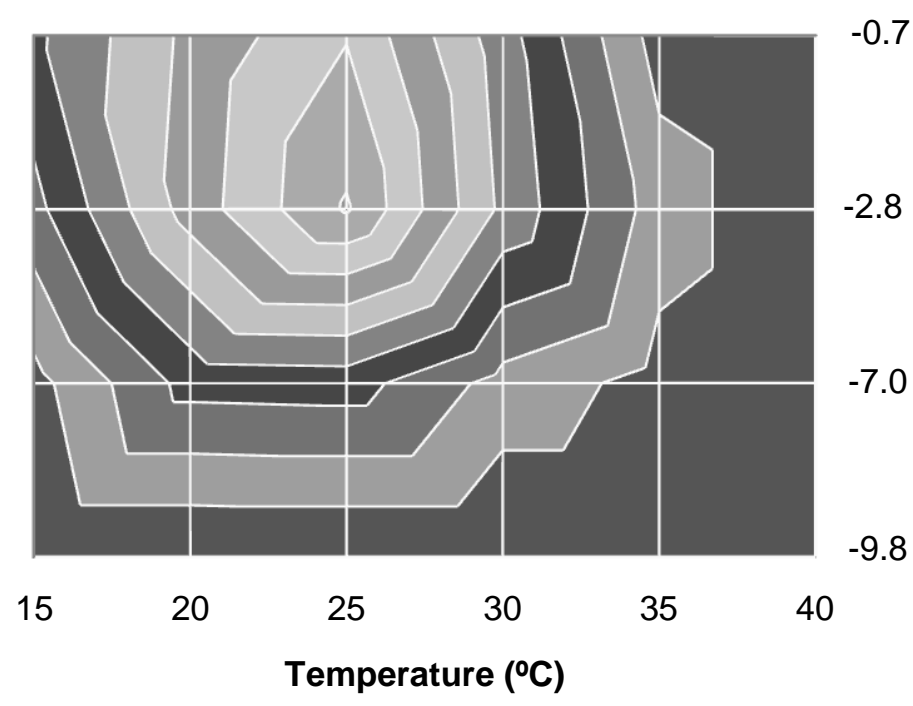

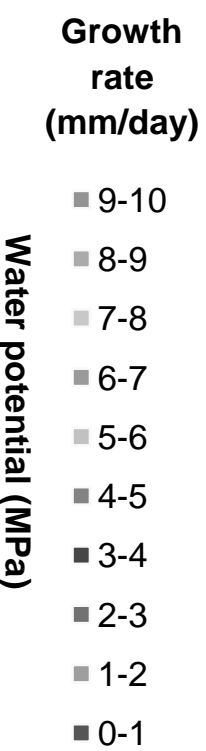

Figure 1: Bidimensional map showing growth rate of $F$. graminearum in relation to temperature and non-ionic solute potential. The values are the mean of three replicates. 


\section{$-0.7 \mathrm{MPa}$}

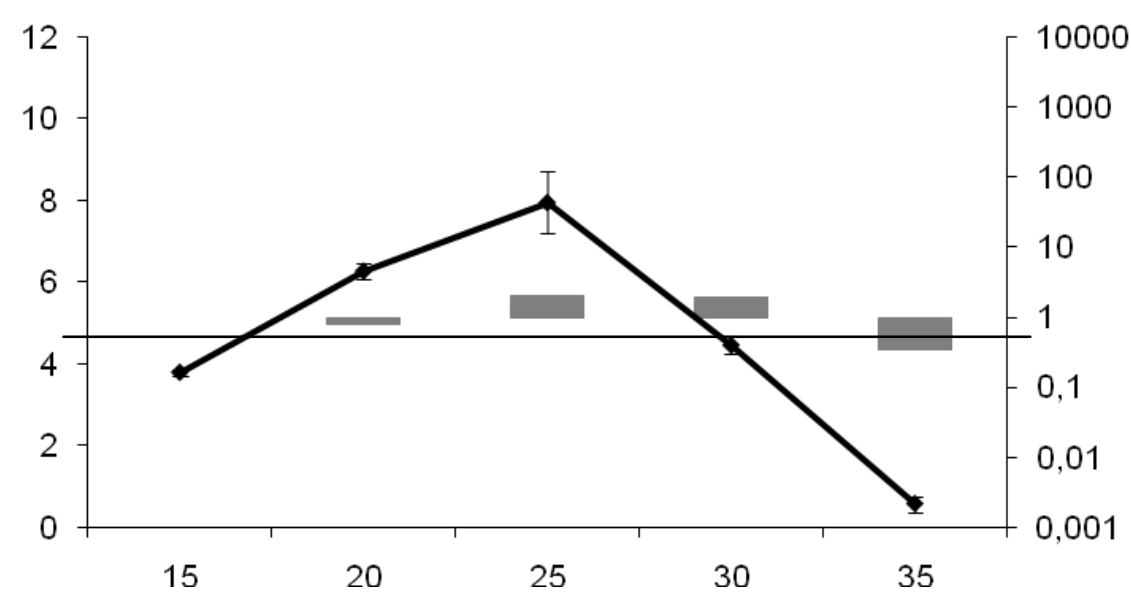

\section{$-2.8 \mathrm{MPa}$}

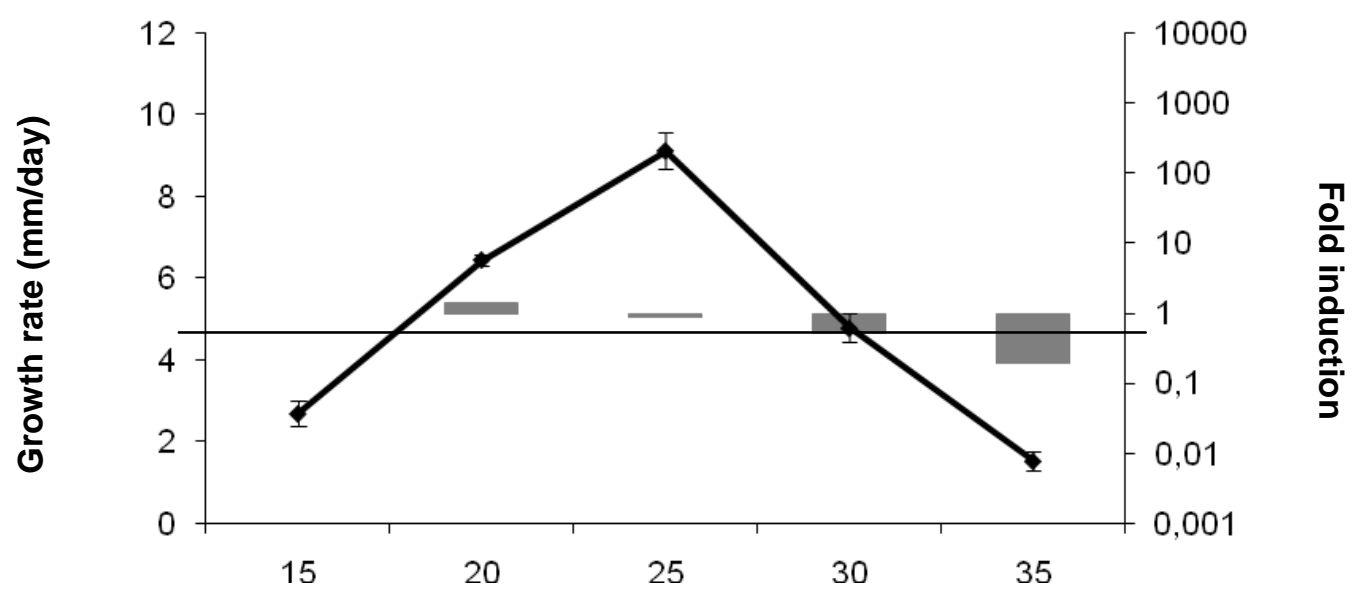

\section{$-7.0 \mathrm{MPa}$}

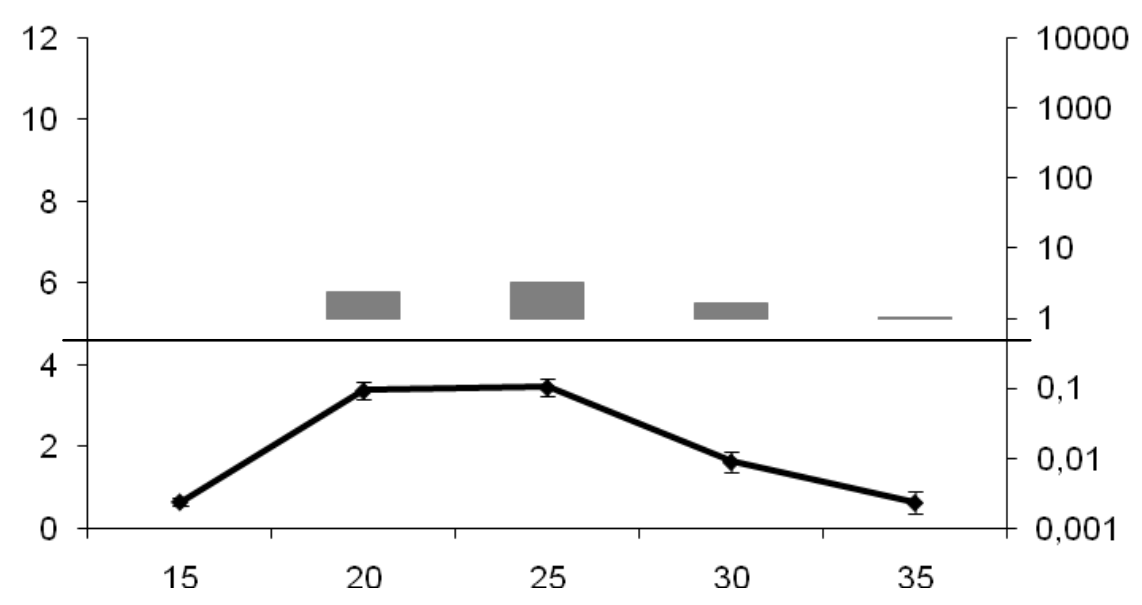

Temperature (으) 
International Journal of Food Microbiology, Volume 140, Issue 2-3 (2010) 169-174.

Figure 2: Comparison of induction of growth rate $(\bullet)$ and TRI5 gene expression $(\square)$ in response to non-ionic (glycerol) osmotic potential in F. graminearum for 10 days at three different solute potentials (-0.7, -2.8 and $-7.0 \mathrm{MPa})$ and five temperatures $(15,20$, 25,30 and $\left.35^{\circ} \mathrm{C}\right)$. The measured quantity of the cDNA in each experiment was normalized using $\mathrm{C}_{\mathrm{T}}$ values obtained for TUB2 cDNA amplifications run in the same plate. The values represent the number of times $T R I 5$ is expressed in each experiment compared to its respective culture incubated at $15^{\circ} \mathrm{C}$ (set at 1.00 ). The results are averages of the three independent repetitions. 


\section{$-0.7 \mathrm{Mpa}$}

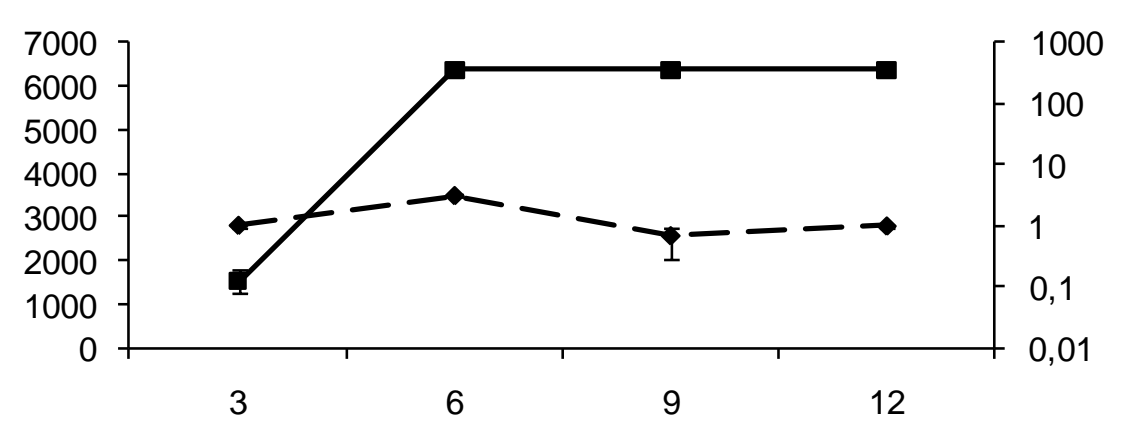

\section{$-2.8 \mathrm{MPa}$}

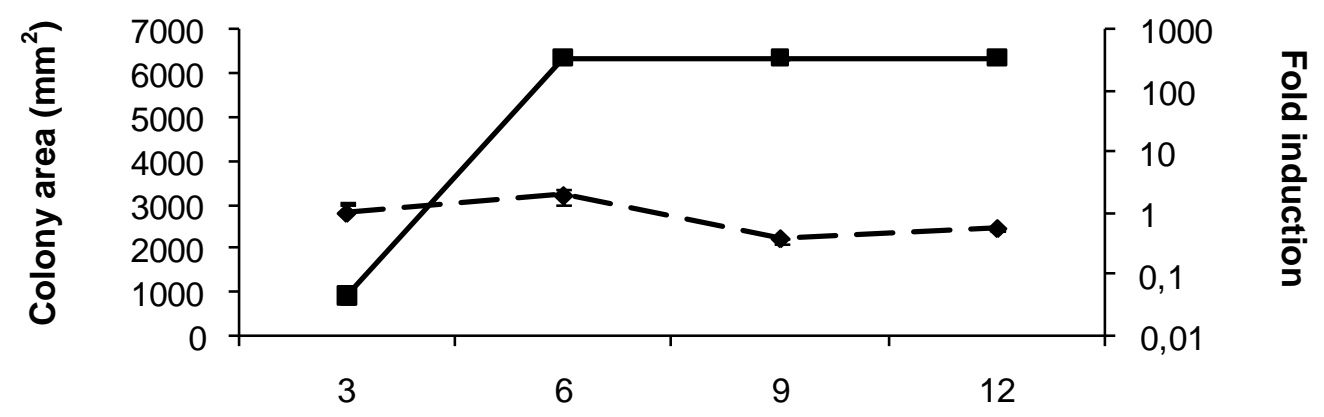

\section{-7.0 MPa}

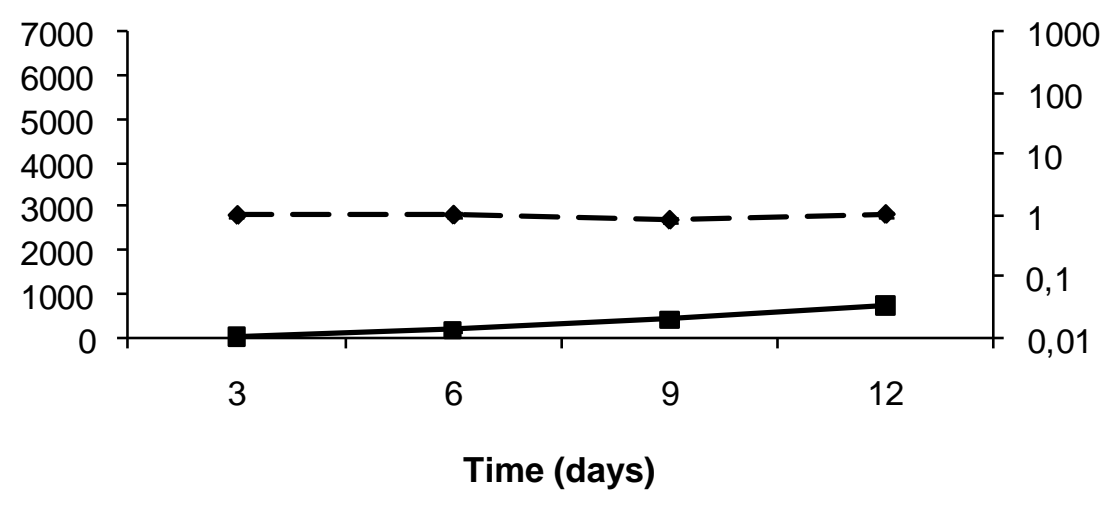

Figure 3: Temporal kinetics study of the effect of ionic $(\mathrm{NaCl})$ solute potential on relative colony size $(\mathbf{\square})$ and induction of $T R I 5$ gene expression $(\diamond)$ of $F$. graminearum at 
International Journal of Food Microbiology, Volume 140, Issue 2-3 (2010) 169-174.

$25^{\circ} \mathrm{C}$ at three different solute potentials $(-0.7,-2.8$ and $-7.0 \mathrm{MPa})$. The measured quantity of the cDNA in each of the experiments was normalized using the $\mathrm{C}_{\mathrm{T}}$ values obtained for the TUB2 cDNA amplifications run on the same plate. The values represent the number of times $T R / 5$ is expressed in each experiment compared to its respective 3-day-old culture of the F. graminearum strain (set at 1.00). The results are average of the three independent repetitions. 